\title{
Isolamento, Caracterização Cultural-Morfológica, Patogenicidade e Serologia de Streptomyces spp. da Batata
}

\author{
Ivan H. Fischer*, Hiroshi Kimati \& Marise C. Martins \\ Departamento de Entomologia, Fitopatologia e Zoologia Agrícola, Escola Superior de Agricultura "Luiz de Queiroz", \\ Universidade de São Paulo, Cx. Postal 9, CEP 13418-900, Piracicaba, SP, fax (019) 3434-4839, e-mail: ihfische @ esalq.usp.br
}

(Aceito para publicação em 15/08/2003)

Autor para correspondência: Ivan H. Fischer

FISCHER, I.H., KIMATI, H. \& MARTINS, M.C. Isolamento, caracterização cultural-morfológica, patogenicidade e serologia de Streptomyces spp. da batata. Fitopatologia Brasileira 28:650-655. 2003.

\section{RESUMO}

O presente trabalho testou quatro métodos de isolamento de Streptomyces spp. em tubérculos de batata (Solanum tuberosum) com sarna comum, superficial e profunda, caracterizando os isolados quanto a morfologia, serologia e patogenicidade. Para o isolamento foram testados: meio de cultura ágar-água a $\mathrm{pH}$ 10; meio contendo antibióticos; meio de asparagina e meio de quitina. O meio ágar-água pH 10 foi o mais eficaz no isolamento de Streptomyces spp. com média de 129 colônias/placa, além de ser de fácil preparo, menor custo e proporcionar melhor visualização das colônias. No meio de antibiótico verificou-se média de $54 \%$ dos fragmentos de tubérculos plaqueados com crescimento de Streptomyces spp. Já nos meios de asparagina e quitina a média foi de 36,3 e 2,5 colônias/placa, respectivamente. Para caracterização dos isolados obtidos utilizouse o meio de extrato de levedura e malte. As colônias originadas apresentaram coloração que variou de cinza a marrom e de branco a creme, com ou sem produção de pigmento, com cadeias de esporos flexuosas ou espiraladas, de tamanho variável e produzindo ou não micélio aéreo em colônias com cadeias espiraladas. Dezenove isolados, representando esses diferentes tipos, foram inoculados na batata cv. Monalisa por infestação de solo autoclavado, antes da semeadura dos tubérculos-sementes. Sintomas típicos da doença foram verificados 14 semanas após a inoculação, para oito isolados. Anti-soros produzidos em coelhos contra três isolados fitopatogênicos apresentaram reação serológica (dupla difusão em gel-ágar de Ouchterlony) para os antígenos homólogos e para poucos antígenos heterólogos, porém os isolados de Streptomyces com patogenicidade confirmada não apresentaram antígenos em comum.

Palavras-chave adicionais: sarna comum, $\mathrm{pH}$, dupla difusão.

\begin{abstract}
Isolation, cultural and morphological characterization, pathogenicity and serology of Streptomyces spp. from potato

Four methods of isolation of common superficial and deep scab were tested with the purpose of characterizing the isolates of Streptomyces scabies according to morphological and serological criteria and their pathogenicity. For isolation, obtained in water-agar at $\mathrm{pH} 10$, a medium containing antibiotics, asparagine medium and coloidal quitin medium were tested. Water-agar $\mathrm{pH} 10$ was the most efficient medium, giving rise to 129 colonies/Petri dishes, besides being of easy preparation, lower cost and giving better visualization of the colonies. The antibiotic medium gave an average of $54 \%$ of plated potato tuber fragments that yielded Streptomyces spp. growth. Asparagine and coloidal quitin showed averages of 36,3 and 2,5 colonies/Petri dish, respectively. For characterization of isolates, the

yeast extract and malt medium were used, resulting in colony colors ranging from gray to brown and from white to cream, with and without production of pigment. The colonies formed flexuous or spiral spore chains, with variable size and producing or not aerial mycelium in spiral colonies. Nineteen isolates representing the different cultural and morphological types were inoculated in potato (Solanum tuberorum) $\mathrm{cv}$. Monalisa through infestation of sterilized soil before the sowing of the seed tubers. Typical symptoms of the disease were reproduced 14 weeks after inoculation by eight isolates. Antisera produced in rabbits against three pathogenic isolates showed serological reaction (double diffusion in Ouchterlony gel-agar) for the homologous antigens and for few heterologous antigens. Streptomyces spp. isolates with confirmed pathogenicity did not show antigens in common.
\end{abstract}

\section{INTRODUÇÃO}

A cultura da batata (Solanum tuberosum L.) tem sofrido importantes perdas econômicas, devidas à sarna comum que ocasiona lesões corticosas nos tubérculos, tanto superficiais quanto profundas. A doença é causada por diferentes espécies e raças de bactérias do gênero Streptomyces, que formam conídios e filamentos, estruturas normalmente relacionadas a fungos (Labruyere, 1971).

*Bolsista da FAPESP - Processo 99/11703-3
A espécie S. scabies (Thaxter) Waksman \& Henrici é a mais encontrada causando a sarna comum, mas outras como S. acidiscabies Lambert \& Loria, S. turgidiscabies Miyajima, Tanaka, Takeuchi \& Kuninaga e S. caviscabies Goyer, Faucher $\&$ Beaulieu também podem incitar sintomas da doença. Estas quatro espécies diferenciam-se entre si por critérios morfológicos, fisiológicos e genéticos (Faucher et al., 1995; Takeuchi et al., 1996; Miyajima et al., 1998).

A espécie $S$. scabies produz esporos de coloração cinza, em forma de barril, arranjados em cadeia, formando um espiral, 
Isolamento, caracterização cultural-morfológica, patogenicidade e serologia...

medindo $0,8-1,7 \times$ x 0,5-0,8 $\mu \mathrm{m}$, produz melanina, utiliza todos os açúcares empregados na caracterização de espécies de Streptomyces, conforme recomendado pelo Projeto Internacional de Streptomyces spp. (Shirling \& Gottlieb, 1966), é sensível à estreptomicina; é encontrada em solos secos, neutros a alcalinos, não se desenvolvendo em $\mathrm{pH}$ abaixo de 5 (Lambert \& Loria's, 1989; Waterer, 2002)

A espécie $S$. acidiscabies diferencia-se morfologicamente de $S$. scabies pela produção de esporos de coloração esbranquiçada a avermelhada formados em cadeias flexuosas e pela não produção do pigmento melanina. Não é capaz de utilizar rafinose como única fonte de carbono e consegue se desenvolver em meio de cultura a pH 4 (Lambert \& Loria, 1989).

A espécie $S$. turgidiscabies produz esporos em cadeia flexuosa de coloração cinza; não produz melanina ou outro pigmento difusível e apresenta baixa similaridade ao nível de DNA com as outras espécies causadoras da sarna comum (Miyajima et al., 1998; Kim et al., 1998). Streptomyces caviscabies diferencia-se de S. turgidiscabies por apresentar os esporos de coloração dourada e também pela baixa similaridade ao nível de DNA (Goyer et al., 1996a).

Estudos taxonômicos realizados no Japão com 35 isolados patogênicos de Streptomyces spp., provenientes de tubérculos de batatas, permitiram a divisão desses isolados em dois grupos, baseados na morfologia da cadeia de esporos: espiralada ou flexuosa (Tashiro et al., 1990). No leste do Canadá, isolados de batata causadores da sarna comum foram divididos em três grupos fenotípicos (Faucher et al., 1992): isolados do primeiro grupo formavam colônias bronzeadas para marrom, esporos de coloração cinza, dispostos em cadeia espiralada e produção de melanina; isolados do segundo grupo geravam colônias amarelo-ouro para castanho brilhantes, esporos brancos em cadeias flexuosas e não produção de melanina; isolados do terceiro grupo apresentavam as mesmas características morfológicas do segundo grupo, entretanto, utilizavam somente a rafinose como fonte de carbono, assim como os isolados do primeiro grupo. Todos os isolados mostravam-se sensíveis à estreptomicina.

A sarna comum pode formar lesões corticosas nos tubérculos, superficiais ou profundas. Os sintomas da sarna profunda podem ser causados por Streptomyces spp. dependendo das condições ambientes, virulência da raça e resistência da cultivar de batata (Lorang et al., 1995; Toth et $a l ., 2001)$. Entretanto, a correlação entre a secreção de enzimas hidrolíticas e a severidade dos sintomas tem sido estabelecida. Isolados de S. scabies causadores de lesões superficiais não mostraram atividade proteolítica (Faucher et al., 1995). Raças da bactéria provenientes de Quebec, causadoras de sarna profunda, exibiram atividades proteolítica e celulolítica superiores às associadas a raças isoladas da casca do tubérculo de batata com a sarna superficial (Cortean \& Beaulieu citado por Goyer et al., 1996b). Thaxtomins, um grupo de fitotoxinas, parece ter importante relação na patogenicidade, o que foi confirmado por King et al. (1991) e Healy et al. (2000), que obtiveram correlação positiva entre produção dessa fitotoxina e patogenicidade.
O isolamento de actinomicetos de amostras de solos e de tubérculos infetados com a sarna é relativamente difícil, devido ao grande número de contaminantes. Vários métodos de isolamento foram desenvolvidos, destacando-se o tratamento do inóculo com fenol (Lawrence, 1956) e o tratamento do solo úmido com $\mathrm{CaCO}_{3}$ para aumentar o $\mathrm{pH}$, juntamente com o ajuste do $\mathrm{pH}$ do meio de farinha de soja na faixa de 7,9 a 8,1 (Tsao et al., 1960). Hsu \& Lockwood (1975) relataram a eficácia do isolamento e quantificação de actinomicetos de amostras de água em meio de ágar acrescido de quitina coloidal a $0,4 \%$ e sais minerais, ajustado a $\mathrm{pH} 8,0$.

Moyer \& Echandi (1986) identificaram S. ipomoea (Person \& Martin) Waks \& Henrici agente causal da sarna da batata doce [Ipomea batata (L.) Lam], em culturas puras, através das técnicas serológicas de dupla difusão e ELISA. Para obtenção deste resultado, imunizaram coelhos com suspensões homogeneizadas de células de S. ipomoea, combinada com adjuvante completo de Freund, aplicando injeções por via intramuscular.

Frente ao exposto, os objetivos do presente trabalho foram testar quatro metodologias de isolamento de Streptomyces spp. de tubérculos de batata e caracterizar os isolados quanto a critérios morfológicos-culturais, patogenicidade e análises sorológicas pelo método de dupla difusão.

\section{MATERIALEMÉTODOS}

Os experimentos foram realizados no Laboratório de Fitopatologia e na área experimental pertencentes ao Departamento de Entomologia, Fitopatologia e Zoologia Agrícola da Escola Superior de Agricultura "Luiz de Queiroz", Universidade de São Paulo, Campus de Piracicaba, SP.

\section{Isolamento de Streptomyces spp. de tubérculos de batata}

Tubérculos de batata com sarna comum superficial e profunda foram obtidos de campos comerciais de batata, localizados nas cidades de São Miguel Arcanjo/SP, Piedade/ SP e Ponta Grossa/PR, pertencentes a agricultores filiados à Associação de Bataticultores do Sudoeste Paulista (ABASP) e à Associação Brasileira da Batata (ABBA). As quatro metodologias de isolamento avaliadas foram:

A) Porções de $1 \mathrm{~g}$ do tubérculo lesionado foram lavadas em água corrente, desinfestadas com álcool $70 \%$ e maceradas em $1 \mathrm{ml}$ de água esterilizada. Espalhou-se $40 \mu \mathrm{l}$ dessa suspensão, com o auxílio da alça de Drigalsky, em placas contendo $20 \mathrm{ml}$ de ágar-água (AA) ajustado a pH $10(\mathrm{NaOH} 0,5 \mathrm{~N})$, adaptado de Ho \& Ko, (1979) (AA pH 10).

B) Porções de $0,5 \mathrm{~cm}^{2}$ de tubérculos foram colocadas em solução de fenol e água esterilizada (1:140) por $10 \mathrm{~min}$, seguido de duas lavagens em água esterilizada por $15 \mathrm{~min}$, e posterior aquecimento em água a $55^{\circ} \mathrm{C}$ por $30 \mathrm{~min}$ (Faucher et al., 1992). Foram transferidos cinco fragmentos de tubérculos por placa contendo meio constituído de 1,2\% de ágar, $50 \mathrm{mg}$ de nistatina, $5 \mathrm{mg}$ de sulfato de polimixina $\mathrm{B}, 1 \mathrm{mg}$ de penicilina $\mathrm{G}$ de sódio e $50 \mathrm{mg}$ de cicloheximida por litro (antibiótico).

C) Uma gota de $40 \mu \mathrm{l}$ da suspensão, obtida conforme 
item A, foi transferida para $10 \mathrm{ml}$ de solução de fenol (1:140), agitando-se por $10 \mathrm{~min}$; transferiu-se $40 \mu \mathrm{l}$ para $12 \mathrm{ml}$ do meio cultura de glicose-asparagina-ágar ajustado a $\mathrm{pH} 6,5$ a $45^{\circ} \mathrm{C}$ (Lawrence, 1956) (asparagina).

D) Porções de $1 \mathrm{~g}$ do tubérculo doente foram lavadas em água corrente, desinfestadas com álcool $70 \%$ e maceradas em $1 \mathrm{ml}$ de tampão fosfato $0,1 \mathrm{M}$ (pH 8,5), espalhando-se $40 \mu \mathrm{l}$ do macerado sobre meio de quitina com propriedades coloidais, preparado com tampão fosfato $0,1 \mathrm{M}$ (Lingappa \& Lockwood, 1962) (quitina).

A eficiência dos métodos de isolamento de Streptomyces spp. em tubérculos de batata baseou-se na contagem do número de colônias de Streptomyces spp., bactérias não filamentosas e fungos, após dez dias de incubação no escuro, a $28^{\circ} \mathrm{C}$.

A purificação dos isolados de Streptomyces spp., obtidos nos diferentes métodos de isolamento, foi realizada após repicagens sucessivas em seus respectivos meios de isolamento. Buscou-se repicar as colônias mais individualizadas, distantes de colônias de bactérias não filamentosas e fungos. Para isso, porções das colônias foram coletadas com uma agulha e espalhadas no meio com a alça de Drigalsky, na presença de $40 \mu \mathrm{l}$ de água esterilizada. Após obtenção dos isolados puros, os mesmos foram repicados para meio de extrato de levedura e malte (YME), que por ser um meio rico, facilitou a caracterização morfológica e cultural dos isolados.

\section{Caracterização morfológica das colônias}

A análise morfológica foi realizada visualmente e através de microscopia óptica, avaliando-se o formato das cadeias de esporos, a coloração das colônias e a produção de pigmentos em meio de cultura.

\section{Testes de patogenicidade}

Batatas-sementes da cultivar Monalisa foram desinfestadas superficialmente com hipoclorito de sódio $(0,5 \%)$, por $15 \mathrm{~min}$, enxaguadas em água destilada por mais 15 min e plantadas em sacos de polietileno preto com capacidade de $4 \mathrm{Kg}$, mantidos em casa de vegetação a temperatura média de $28^{\circ} \mathrm{C}$. O substrato utilizado, composto de terra, esterco bovino e areia, na proporção de 2:1:1, apresentando $\mathrm{pH}$ em água de 6,3, foi autoclavado e previamente infestado com uma suspensão de Streptomyces spp., incorporada nos primeiros $10 \mathrm{~cm}$, à razão de uma placa de Petri de $9 \mathrm{~cm}$ de diâmetro por quilo de solo. Procurou-se manter a umidade do solo baixa, principalmente durante a fase de tuberização. Foi realizada uma adubação com nitrato de cálcio na proporção de $6 \mathrm{~g}$ por saco, aos 25 dias do plantio. A distribuição dos sacos foi inteiramente ao acaso, com quatro repetições (plantas) por isolado, de um total de 19 isolados, representando os diferentes tipos morfológicos encontrados. O experimento foi repetido duas vezes (setembro de 2000 e março de 2001).

A avaliação dos sintomas da sarna comum foi realizada 14 semanas após o plantio, efetuando-se em seguida o reisolamento em AA pH 10 de Streptomyces spp. dos tubérculos formados e comparação dos diferentes isolados obtidos em YME.

\section{Produção de anti-soro}

As colônias bacterianas usadas para produção do antisoro foram suspensas em $0,02 \mathrm{M}$ Tris- $\mathrm{HCl}$ ( $\mathrm{pH} 7,2$ ). A suspensão foi homogeneizada e centrifugada a $10.000 \mathrm{~g}$ por $10 \mathrm{~min}$. O precipitado foi ressuspenso e ajustado para uma absorbância igual a 1,4 a $280 \mathrm{~nm}$. Dessa suspensão foi retirada uma alíquota de $1 \mathrm{ml}$, que foi emulsionada com $1 \mathrm{ml}$ de coadjuvante Freund completo e injetado por via intramuscular na perna traseira de um coelho jovem, imunologicamente competente (quatro meses). Injeções foram aplicadas semanalmente. As sangrias foram realizadas a partir da quarta semana após o inicio das injeções (Moyer \& Echandi, 1986).

\section{Detecção da bactéria mediante teste imunológico}

Preparou-se uma suspensão bacteriana dos isolados em 0,02 M Tris- $\mathrm{HCl}, \mathrm{pH} \mathrm{7,2,} \mathrm{contendo} \mathrm{0,15} \mathrm{M} \mathrm{NaCl,}$ padronizando a mesma fotometricamente conforme citado para produção de anti-soro. A suspensão padronizada foi empregada para as reações sorológicas.

Os testes serológicos foram realizados empregando-se a técnica de dupla difusão em gel - ágar de Ouchterlony. Colocou-se $5 \mathrm{ml}$ de uma solução fundente de agarose (Moyer \& Echandi, 1986) em lâminas de vidro para microscopia, perfurando-se esta camada após a solidificação, com o auxílio de um conjunto de seis cilindros ocos de 0,4 cm de diâmetro, dispostos hexagonalmente, e um cilindro central, sendo a distância entre os vértices do hexágono de $0,5 \mathrm{~cm}$.

Os antígenos reagentes foram colocados nos poços circundantes e o anti-soro no poço central, sendo que o preenchimento dos poços foi feito duas vezes dentro de um intervalo de $30 \mathrm{~min}$. As lâminas foram mantidas em câmara úmida por dois dias, quando se procedeu a avaliação dos testes serológicos. Esta mesma técnica foi utilizada para a titulação dos anti-soros e antígenos, os quais foram diluídos em salina tamponada por fatores de $2\left(2^{-n}, \mathrm{n}\right.$ variando de 1 a 5$)$. As reações entre antígenos e anti-soros foram determinadas para os diferentes isolados, comparando-se com os soros.

\section{RESULTADOSE DISCUSSÃO}

\section{Isolamento de Streptomyces spp. de tubérculos de batata}

Os números de colônias de microorganismos isolados por placa, para as diferentes metodologias testadas estão expressos na Tabela 1.

O meio de cultura AA pH 10 foi o que propiciou maior número de isolados de Streptomyces spp., com média de 129 colônias/placa, permitindo fácil observação da morfologia das colônias com o auxílio da microscopia óptica, apresentando ainda as vantagens da praticidade e baixo custo de preparo e isolamento. As colônias crescidas sobre o meio AA pH 10 apresentaram reduzido desenvolvimento e baixa esporulação, o que dificultou a observação da coloração das colônias, as quais caracterizaram-se por uma tonalidade cinza.

O meio de antibiótico também foi eficiente no isolamento de Streptomyces spp., alcançando uma média de 2,7 colônias/ placa, o que, apesar de ser bem inferior ao número obtido com 
Isolamento, caracterização cultural-morfológica, patogenicidade e serologia...

TABELA 1 - Eficácia de diferentes metodologias de isolamento de microrganismos (bactérias do gênero Streptomyces, bactérias não filamentosas e fungos) de tubérculos de batata (Solanum tuberosum)

\begin{tabular}{|c|c|c|c|c|c|c|c|c|c|c|c|c|}
\hline \multirow{3}{*}{ Cultivar } & \multicolumn{12}{|c|}{$\mathbf{N}^{0}$ de colônias */placa nos meios de } \\
\hline & \multicolumn{3}{|c|}{ AA pH 10} & \multicolumn{3}{|c|}{ Antibiótico } & \multicolumn{3}{|c|}{ Asparagina } & \multicolumn{3}{|c|}{ Quitina } \\
\hline & Strept. & Bactéria & Fungo & Strept. & Bactéria & Fungo & Strept. & Bactéria & Fungo & Strept. & Bactéria & Fungo \\
\hline Monalisa 1 & 061,4 & 069,7 & 2,9 & 3,6 & 5,0 & 0,0 & 6,2 & 227,2 & 0,9 & 25,0 & 483,1 & 08,6 \\
\hline Bintje & 033,0 & 085,0 & 1,7 & 2,6 & 5,0 & 0,0 & 0,4 & 005,8 & 0,1 & 35,7 & 560,2 & 51,3 \\
\hline Monalisa 2 & 114,0 & 142,3 & 3,4 & 2,0 & 5,0 & 0,3 & 0,2 & 007,2 & 0,2 & 34,4 & 533,0 & 13,2 \\
\hline Atlantic & 145,7 & 535,8 & 0,1 & 2,7 & 5,0 & 0,6 & 1,7 & 001,8 & 0,1 & 58,9 & 783,7 & 20,5 \\
\hline Monalisa 3 & 290,2 & 210,4 & 4,8 & 2,8 & 5,0 & 0,6 & 4,0 & 034,7 & 2,3 & 27,6 & 965,2 & 06,4 \\
\hline Média Geral & 128,9 & 208,6 & 2,6 & 2,7 & 5,0 & 0,3 & 2,5 & 055,3 & 0,7 & 36,3 & 665,0 & 20,0 \\
\hline
\end{tabular}

*Média de duas repetições de cinco placas cada.

o meio AA pH 10, ocorreu devido a metodologia utilizada. No meio de antibiótico, foram plaqueados fragmentos de tubérculo, ao contrário do $\mathrm{AA} \mathrm{pH} 10$ onde se plaqueou a suspensão de tubérculos macerados por toda a placa. O meio de antibiótico permitiu a visualização da coloração das colônias de Streptomyces spp. sobre os fragmentos de tubérculos; apresentou, porém, contaminação de bactérias não filamentosas na base desses fragmentos e dificuldade para a observação da morfologia das colônias com microscopia, pois as colônias não haviam se desenvolvido, até os dez dias, sobre o meio de cultura, iniciando-se ao redor dos quinze dias. Além disso, o preparo do meio era de alto custo e trabalhoso.

O número de colônias de Streptomyces spp. obtidas por placa em meio de glicose-asparagina-ágar, apesar de ter sido semelhante ao observado no meio de antibiótico, pode ser considerado inferior a este, pois mais de $50 \%$ das colônias de microorganismos apresentaram um crescimento interno no meio de cultura, dificultando a identificação dos mesmos.

O meio de quitina coloidal foi menos eficaz em relação ao número de isolados de Streptomyces spp. obtidos, quando comparado ao meio AA pH 10, mas as colônias apresentaram desenvolvimento e características semelhantes às crescidas no mesmo meio.

A elevação do $\mathrm{pH}$ do meio de cultura e o tratamento dos fragmentos de tubérculo de batata infetados, com fenol, favoreceram o isolamento de Streptomyces spp., conforme já descrito na literatura (Lawrence, 1956; Tsao et al., 1960; Hsu \& Lockwood, 1975; Ho \& Ko, 1979).

\section{Análise morfológica}

De acordo com a caracterização morfológica e cultural dos isolados (Tabela 2), as colônias apresentaram crescimento radial em todos os meios de cultura avaliados.

Os diferentes isolados de Streptomyces encontrados foram correlacionados com suas respectivas amostras de tubérculos de batata (Tabela 3).

Confrontando-se a morfologia das colônias de Streptomyces spp. obtidas, com as encontradas na literatura, sugere-se que as colônias $a, b, d, e, f, g, h$ e $i$, de cadeias de esporos espiraladas e coloração cinza, correspondem a $S$. scabies, conforme citado por Lambert \& Loria's (1989).

As colônias $j, n$ e $o$ apresentaram cadeias de esporos flexuosas e coloração cinza, características descritas para $S$. turgidiscabies (Miyajima et al., 1998; Kim et al., 1998).

Encontraram-se colônias flexuosas brancas a avermelhadas $(l, p, q$ e $r)$, que não produziram pigmentos difusíveis no meio de cultura, conforme descrito para $S$. acidiscabies. Também se encontrou uma colônia com cadeias de esporos flexuosas de coloração cinza escuro, que liberou pigmento violeta no meio de cultura $(m)$, não sendo possível relacioná-la a uma espécie definida.

\section{Testes de patogenicidade}

Os testes de patogenicidade, seguidos do reisolamento e comparação morfológica dos isolados, evidenciaram a capacidade dos isolados de Streptomyces spp. $b_{2}$ e $b_{3}$ de causar a sarna comum profunda e os isolados $b, e, h, m, o$ e $p$ de causar a sarna comum superficial. Sugere-se, portanto, a existência, no Brasil, das espécies S. scabies (isolados $b, b_{2}$, $b_{3}$, e e h), S. acidiscabies (isolado $p$ ), e $S$. turgidiscabies (isolado $o$ ).

A confirmação da patogenicidade dos isolados de Streptomyces spp. obtidos de tubérculos de batata torna-se sempre necessária, pois há semelhanças morfológicas e culturais entre isolados saprofíticos e patogênicos (Lambert \& Loria, 1989).

\section{Análise sorológica}

Os anti-soros que resultaram em reação serológica foram obtidos após a sétima semana do início das injeções para o isolado $b$ e após a quinta semana para os isolados $b_{3}$ e $o$. Houve reação com os antígenos homólogos até a diluição 1:2 para o anti-soro $b$ e 1:4 para os anti-soros $o$ e $b_{3}$. Em relação aos antígenos houve reação até a diluição de 1:4 para o antígeno $b$ e 1:2 para os antígenos $o$ e $b_{3}$, também com seus respectivos anti-soros.

$\mathrm{O}$ anti-soro $b$ reagiu fortemente com seu antígeno homólogo, evidenciando-se duas linhas de precipitação quando não diluídos, sendo uma linha pouco evidente, que desapareceu quando o antígeno ou anti-soro foram diluídos.

Avaliou-se a especificidade dos anti-soros aos isolados 
I.H. Fischer et al.

TABELA 2 - Caracterização morfológica e cultural de isolados de Streptomyces spp. obtidos de tubérculos de batata (Solanum tuberosum)

\begin{tabular}{|c|c|c|c|c|c|}
\hline \multicolumn{2}{|c|}{ Cadeia de esporos } & \multirow{2}{*}{ Micélio aéreo } & \multirow{2}{*}{ Cor da colônia } & \multirow{2}{*}{$\begin{array}{l}\text { Produção de } \\
\text { pigmentos }^{1}\end{array}$} & \multirow{2}{*}{$\begin{array}{c}\text { Tipo } \\
\text { morfológico }\end{array}$} \\
\hline Formato & Comprimento & & & & \\
\hline \multirow[t]{8}{*}{ Espiralada } & longa & presente & cinza escuro & ausente & $a$ \\
\hline & & & cinza claro & ausente & $b$ \\
\hline & & & branco amarronzado & ausente & $c$ \\
\hline & & ausente & cinza claro & ausente & $d$ \\
\hline & curta & presente & cinza escuro & ausente & $e$ \\
\hline & & & cinza claro & ausente & $f$ \\
\hline & & & marrom acinzentado & marrom & $g$ \\
\hline & & ausente & marrom acinzentado & marrom & $h$ \\
\hline Espiralada e flexuosa & curta & presente & cinza escuro & ausente & $i$ \\
\hline \multirow[t]{8}{*}{ Flexuosa } & longa & ausente & cinza claro & ausente & $j$ \\
\hline & & & branco & ausente & $l$ \\
\hline & & & cinza escuro & violeta & $m$ \\
\hline & média & ausente & cinza escuro & ausente & $n$ \\
\hline & & & marrom acinzentado & ausente & $o$ \\
\hline & & & creme & ausente & $p$ \\
\hline & curta & ausente & branco avermelhado ${ }^{2}$ & ausente & $q$ \\
\hline & & & branco avermelhado ${ }^{3}$ & ausente & $r$ \\
\hline
\end{tabular}

${ }^{1}$ Liberação de pigmentos no meio de cultura YME.

${ }^{2}{ }^{3}$ Alta e baixa produção de filamentos sob o meio de cultura, respectivamente.

TABELA 3 - Amostras de tubérculos de batata (Solanum tuberosum) e seus respectivos isolados de Streptomyces spp.

\begin{tabular}{lcl}
\hline \hline Cultivar & Tipo de sintoma & Isolado \\
\hline Monalisa 1 & superficial & $b, g, h, i, m, n, p$ \\
Bintje & superficial & $c, d, g_{2}, j, m_{2}, o$ \\
Monalisa 2 & superficial & $a, c_{2}, e, f, l, p_{2}$ \\
Atlantic & superficial & $e_{2}, n_{2}, p_{3}, q, r$ \\
Monalisa 3 & profunda & $b_{2}, h_{2}, p_{4}$ \\
Monalisa 4 & profunda & $b_{3}$ \\
\hline 2, 3 e 4Índices atribuídos a isolados de Streptomyces spp. semelhantes \\
\multicolumn{2}{c}{ morfologicamente, porém obtidos de amostras diferentes de batata } \\
(Solanum tuberosum).
\end{tabular}

de Streptomyces spp. utilizados nos testes de patogenicidade (Tabela 4), observando-se que o anti-soro $b$ reagiu com os antígenos $b, f$ e $q$, o anti-soro $o$ reagiu com os antígenos $f, i$ e $o$, e o anti-soro $b_{3}$ reagiu com os antígenos $b_{3}$ e $f$. Há ocorrência de antígenos comuns entre poucos isolados de Streptomyces. Observou-se reação sorológica positiva para os antígenos homólogos.

Comparando-se os dados obtidos nas análises sorológicas com os dos testes de patogenicidade, observou-se que os isolados de Streptomyces spp. com patogenicidade confirmada não apresentaram antígenos em comum. Dentre os poucos isolados que apresentaram antígenos em comum, apenas os isolados correspondentes aos antígenos homólogos foram patogênicos em tubérculos de batata.

Outras ferramentas disponíveis para a identificação das espécies, tais como a hibridização de DNA e atributos fisiológicos (utilização de açúcares, faixa de temperatura e pH para o crescimento, etc.), juntamente com características morfológicas e culturais analisadas no presente trabalho, não permitem até o momento distinguir alguns isolados saprofíticos dos patogênicos à batata (Lambert \& Loria, 1989; Bouchek et al., 2000; Loria et al., 2001).

TABELA 4 - Reação dos anti-soros $b, b_{3}$ e $o$ com os antígenos (isolados) de Streptomyces spp. oriundos de tubérculos de batata (Solanum tuberosum)

\begin{tabular}{cccc}
\hline \hline \multirow{2}{*}{ Antígeno } & \multicolumn{3}{c}{ Anti-soros* } \\
\cline { 2 - 4 }$a$ & $\boldsymbol{b}$ & $\boldsymbol{b}_{3}$ & $\boldsymbol{o}$ \\
\hline$b$ & - & - & - \\
$b_{2}$ & -+ & - & - \\
$b_{3}$ & - & - & - \\
$c$ & - & + & - \\
$d$ & - & - & - \\
$e$ & - & - & - \\
$f$ & + & - & - \\
$g$ & - & + & + \\
$h$ & - & - & - \\
$i$ & - & - & - \\
$j$ & - & - & + \\
$l$ & - & - & - \\
$m$ & - & - & - \\
$n$ & - & - & - \\
$o$ & - & - & - \\
$p$ & - & - & - \\
$q$ & + & - & - \\
$r$ & - & - & - \\
\hline
\end{tabular}

* Reação antígeno - anti-soro: ${ }^{-}$Ausência de linha de precipitação; ${ }^{+}$ uma linha de precipitação; ${ }^{++}$duas linhas de precipitação. 
Isolamento, caracterização cultural-morfológica, patogenicidade e serologia...

\section{AGRADECIMENTOS}

Os autores agradecem à bióloga Sílvia de Afonseca Lourenço pelo auxílio na condução do experimento e ao Engenheiro Agrônomo Natalino Y. Shimoyama pelo fornecimento dos tubérculos de batata.

\section{REFERÊNCIAS BIBLIOGRÁFICAS}

BOUCHEK, M.K., GARDAN, L., NORMAND, P. \& JOUAN, B. DNA relatedness among strains of Streptomyces pathogenic to potato in France: description of three new species, S. europaeiscabiei sp. nov., S. stelliscabiei sp. nov. associated with common scab, and $S$. reticuliscabiei $\mathrm{sp}$. nov. associated with netted scab. International Journal of Systematic and Evolutionary Microbiology 50:91-99. 2000.

FAUCHER, E., SAVARD, T. \& BEAULIEU, C. Characterization of actinomycetos isolated from common scab lesions on potato tubers. Canadian Journal of Plant Pathology 14:197-202. 1992.

FAUCHER, E., PARADIS, E., GOYER, C., HODGE, N.C., HOGUE, R., STALL, R.E. \& BEAULIEU, C. Characterization of Streptomyces causing deep-pitted scab of potato in Québec, Canada. International Journal of Systematic Bacteriology 45:222-225. 1995.

GOYER, C., FAUCHER, E. \& BEAULIEU, C. Streptomyces caviscabies sp. nov., from deep-pitted lesions in potatoes in Québec, Canada. International Journal of Systematic Bacteriology 46:635639. 1996a.

GOYER, C., OTRYSKO, B. \& BEAULIEU, C. Taxonomic studies on streptomycetes causing potato common scab: a review. Canadian Journal of Plant Pathology 18:107-201. 1996b.

HEALY, F.C., WACH, M., KRASNOFF, S.B., GIBSON, D.M. \& LORIA, R. The txtAB genes of the plant pathogen Streptomyces acidiscabies encode a peptide synthetase required for phytotoxin thaxtomin A production and pathogenicity. Molecular Microbiology 38:794-804. 2000.

HO, W.C. \& KO, W.H.; Alkalized water agar as a selective medium for enumerating soil actinomycetes. Phytopathology 69:1031. 1979.

HSU, S.C. \& LOCKWOOD, J.L. Powdered chitin agar as a seletive medium for enumeration of actinomycetes in water and soil. American Society for Microbiology 29:422-426. 1975.

KIM, J.S., PARK, D.H., LIM, C.K, CHOI, Y.C., HANHM, H.I. \& CHO, W.D. Potato common scab by Streptomyces turgidiscabies. Korean Journal of Plant Pathology 14:551-554. 1998.

KING, R.R., LAWRENCE, C.H. \& CLARK, M.C. Correlation of phytotoxin production with pathogenicity of Streptomyces scabies isolates from scab infect tubers. Journal of American Potato Association 68:675-680. 1991.

LABRUYÈRE, R.E. Common scab and its control in seed potato crops. Centre for Agricultural Publishing and Documentation 767:1-
72. 1971.

LAMBERT, D.H. \& LORIA, R. Streptomyces scabies sp. nov., nom. rev. International Journal of Systematic Bacteriology 39:387-392. 1989.

LAWRENCE, C.H. A method of isolating actinomycetes from scabby potato tissue and soil with minimal contamination. Canadian Journal of Botany 34:44-47. 1956.

LINGAPPA, Y. \& LOCKWOOD, J.L. Chitin media for selective isolation and culture of actinomycetes. Phytopathology 52:317-323. 1962.

LOPES, C.A. Doenças causadas por bactérias em batata. Informe Agropecuário18:36-53. 1996.

LORANG, J.M., LIU, D., ANDERSON, N.A. \& SCHOTTEL, J.L. Identification of potato scab inducing and supressive species of Streptomyces. Phytopathology 85:261-268. 1995.

LORIA, R., CLARK, C.A. BUKHALID, R.A. \& FRY, B. A. Streptomyces spp. In: Schaad, N.W., Jones, J.B. \& Chun, W. (Eds). Laboratory guide for identification of plant pathogenic bacteria, 3nd ed. St. Paul, American Phytopathological Society. 2001. pp.236-249.

MIYAJIMA, K., TANAKA, F., TAKEUCHI, T. \& KUNINAGA, S. Streptomyces turgidiscabies sp. nov. International Journal of Systematic Bacteriology 48:495-502. 1998.

MOYER, J.W. \& ECHANDI, E. Serological detection and identification of Streptomyces ipomoea. Plant Disease 70:516-518. 1986.

SHIRLING, E.B. \& GOTTLIEB, D. Methods for characterization of Streptomyces species. International Journal of Systematic Bacteriology 16:313-340. 1966.

TAKEUCHI, T., SAWADA, H., TANAKA, F. \& MATSUDA, I. Philogenetic analysis of Streptomyces spp. causing potato scab based on 16S rRNA sequences. International Jounal of Systematic Bacteriology 46:476-479. 1996.

TASHIRO, N., MIYASHITA, K. \& SUZUI, T. Taxonomic studies on the Streptomyces species isolated as causal organisms of potato common scab. Annals of the Phytopathological Society of Japan 56:73-82. 1990.

TOTH, L., MAEDA, M., TANAKA, F. \& KOBAYASHI, K. Isolation and identification of pathogenic strains of Streptomyces acidiscabies from netted scab lesions of potato tubers in Hokkaido (Japan). Acta Microbiologica et Immunologica Hungarica 48:575585. 2001.

TSAO, P.H., LEBEN, C. \& KEITT, G.W. An enrichment method for isolating actinomycetes that produce diffusible antifungal antibiotics. Phytopathology 50:88-89. 1960.

WATERER, D. Impact of high soil $\mathrm{pH}$ on potato yields and grade losses to common scab. Canadian Journal of Plant Science 82:585586. 2002. 